In Orchiston, W. (ed.), 2005. The New Astronomy: Opening the Electromagnetic Window and Expanding our View of Planet Earth. Dordrecht, Springer. Pp. 71-92.

\title{
DR ELIZABETH ALEXANDER: FIRST FEMALE RADIO ASTRONOMER
}

\author{
WAYNE ORCHISTON \\ Anglo-Australian Observatory \& Australia Telescope National Facility, PO Box 296, Epping, \\ NSW 2121, Australia (wo@aaoepp.aao.gov.au)
}
Abstract: $\quad$ During March-April 1945, solar radio emission was detected at $200 \mathrm{MHz}$ by operators of a Royal New Zealand Air Force radar unit located on Norfolk Island. Initially dubbed the 'Norfolk Island Effect', this anomalous radiation was investigated throughout 1945 by British-born Elizabeth Alexander, head of the Operational Research Section of the Radio Development Laboratory in New Zealand. Alexander prepared a number of reports on this work, and in early 1946 she published a short paper in the newly-launched journal, Radio \& Electronics. A geologist by training, Elizabeth Alexander happened to be in the right place at the right time, and unwittingly became the first woman in the world to work in the field that would later become known as radio astronomy. Her research also led to further solar radio astronomy projects in New Zealand in the immediate post-war year, and in part was responsible for the launch of the radio astronomy program at the Division of Radiophysics, CSIRO, in Sydney.

Key words: Radio astronomy, New Zealand, 'Norfolk Island Effect', solar radio emission

I dedicate this paper to Woody Sullivan, who introduced me to Elizabeth Alexander's work.

\section{INTRODUCTION}

Although radio astronomy had its origins in the 1930s through the pioneering efforts of Karl Jansky and Grote Reber (Kellermann and Sheets, 1983), it only blossomed as an emerging scientific discipline after WWII. Part of the reason for this was the technological developments that occurred during the war, particularly those relating to radar (e.g. see Lovell, 1977). 
One of the wartime discoveries that provided an impetus for the post-war focus on radio astronomy was the independent detection of solar radio emission in Denmark (Schott, 1947), the United States (Reber, 1944; Southworth, 1945), England (Hey, 1946), Australia (Orchiston and Slee, 2002) and New Zealand. This paper is about Elizabeth Alexander's investigation of solar radio emission in New Zealand during $1945 .^{1}$

\section{ELIZABETH ALEXANDER: A BIOGRAPHICAL SKETCH}

Frances Elizabeth Somerville Alexander neé Caldwell (Figure 1) was born on 13 December 1908 at Merton, Surrey, but spent her early life in India, where her father was the first Professor of Chemistry at Patna Science College and later was its Principal. At the end of WW I she returned to England and after completing her secondary schooling entered Newnham College, Cambridge, graduating in geology in 1931 with First Class Honours and the Harkness Prize. In 1934 she was awarded a Ph.D. from the same University, with a thesis on the main outcrop of the Aymestry Limestone (A.J.B., 1959).

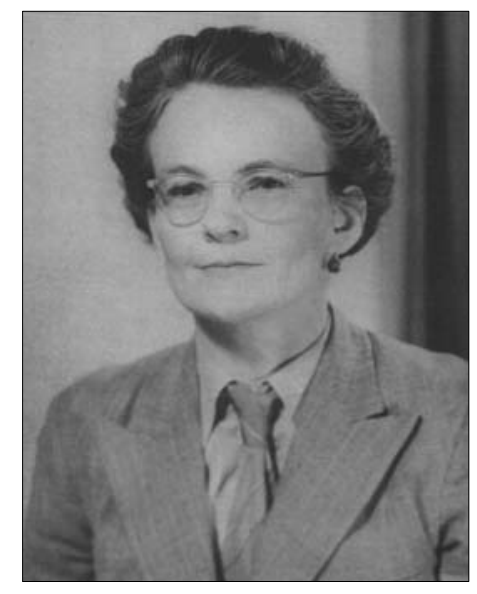

Figure 1. Dr Elizabeth Alexander, 1908-1958 (courtesy: Mary Harris).

In July of the following year Elizabeth married a young New Zealand physicist, Dr Norman S. Alexander, and in 1936 they moved to Singapore when he accepted the Chair in Physics at Raffles College; Elizabeth then began a study of tropical weathering. Their three children, William, Mary and Bernice, were born in Singapore, in 1937, 1939 and 1941 respectively. In 1940 and 1941 Elizabeth worked with the British Royal Navy (at the 
Singapore Naval Base) on radio direction-finding, with the rank of Captain in the Naval Intelligence Service (In Memoriam ..., 1959; Mary Harris, pers. comm., 2005; Obituary, 1959).

In early 1942, as the Japanese invasion of Malaya approached, Elizabeth took her children to safety in New Zealand, intending to return to Singapore with radar equipment from Sydney. But Singapore surrendered before her children were settled, and she was told her husband was dead, so she decided to remain in New Zealand. In April 1942 she was appointed head of the Operations Research Section of the Radio Development Laboratory ${ }^{2}$ in the nation's capital, Wellington (Figure 2). At 33 years of age, she was considerably older than most of those who worked under her, one of whom later recalled: "She was much respected by us much younger folk, because of her experience of the wider world.” (E.R. Collins, pers. comm., 1999). Elizabeth remained head of the Operations Research Section until the end of the War, while Norman Alexander (who in fact had survived) was interned in Changi.

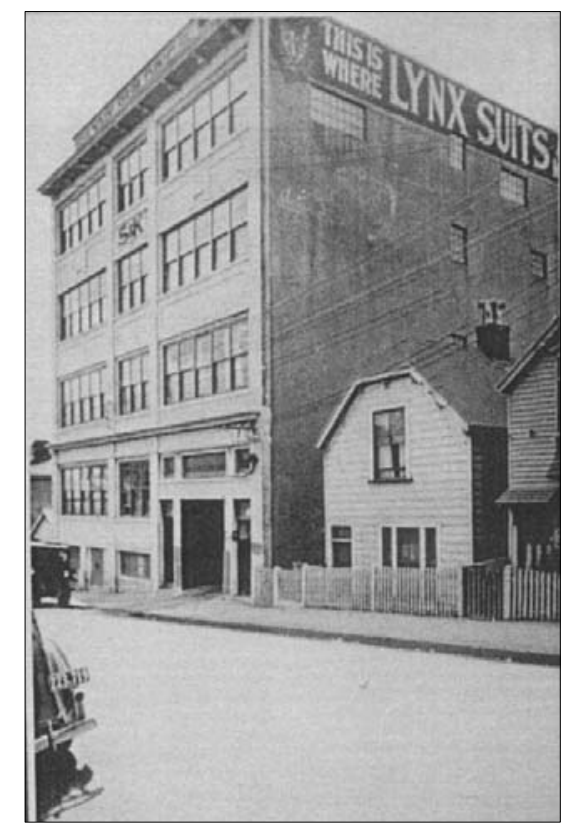

Figure 2. The nondescript office building that housed the Radio Development Laboratory (courtesy: Mary Harris).

The Operational Research Section of the Radio Development Laboratory was involved in New Zealand's wartime radar development program (see Unwin, 1992; World War II Narrative .., 1948), and Elizabeth Alexander 
was responsible for the Section's own research radar unit on Mount Wellington, Wellington, where radar prototypes were operated and tested. She was particularly interested in studying propagational effects and developing fundamental theory so that radar performance could be predicted from meteorological data, and vice versa (Figure 3). Consequently, she became a key player in an ambitious US-British-Australian-New Zealand radiometeorological project to investigate 'anomalous propagation', radiation that appeared to originate from over the horizon. Towards the end of the War, this would evolve into the 'Canterbury Project'. Another-but very different-instance of 'anomalous propagation' that she researched was the 'Norfolk Island Effect', which unwitting took her briefly into a field that would later become known as solar radio astronomy.

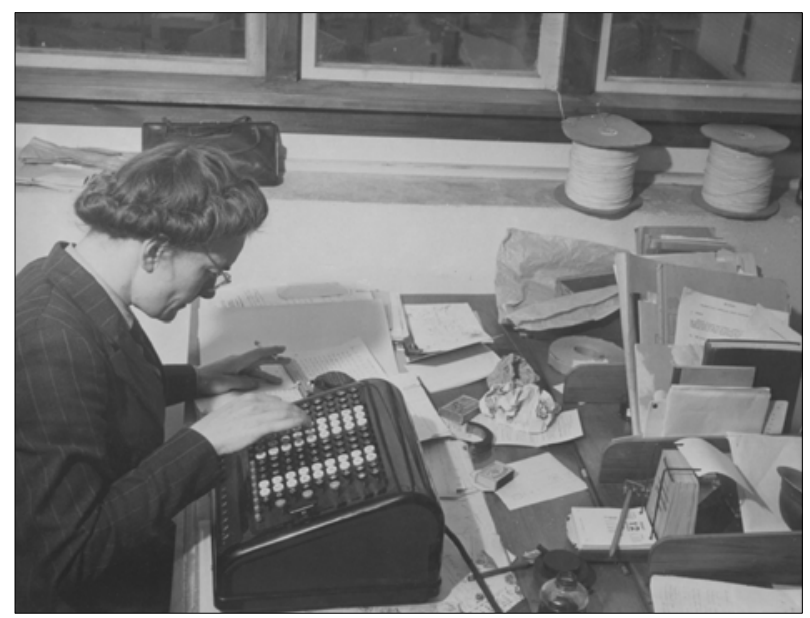

Figure 3: Elizabeth Alexander busy with her calculations (courtesy: Mary Harris).

At the end of the War, Norman Alexander joined Elizabeth and the children in New Zealand, but in March 1946 flew back to Singapore to help reopen Raffles College. Elizabeth and the children remained in Wellington, and in July 1946 sailed for England, where Norman joined them for a while. He was busy acquiring equipment for Raffles College, while Elizabeth wrote up some of her pre-war geological research. Then, in 1947, Norman and Elizabeth returned to Singapore, leaving the children with a relative in England-where they eventually went to boarding schools (Alexander, early 1990s; Mary Harris, pers. comm., 2005).

The next few years saw the evolution of Raffles College into the University of Malaya, with Elizabeth acting as Registrar during the transition period. She then became a geological consultant to various bodies, and in 1949 was appointed Geologist to the Government of Singapore, “... with a 
main task of surveying the island's resources of granite and other useful stone, and in 1950 published a report which included the first reasonably complete geological map of Singapore Island.” (A.J.B., 1959: 140).

In 1952, the Alexanders moved to Ibadan, Nigeria, when Norman accepted the Chair of Physics at the University College. Elizabeth was appointed a Lecturer in Soil Science in the Department of Agriculture, and again began researching tropical weathering. When the University founded a Department of Geology, in 1958, she was promoted to Senior Lecturer and became Head of the Department (Alexander, early 1990s). After just three weeks in this new post she had a stroke, and died a little over one week later, on 15 October 1958; Frances Elizabeth Somerville Alexander was just two months short of her 50th birthday. She was fondly remembered for the “... warm welcome for those who dropped in to the Alexander household, and there are many who are grateful for the hours they have spent there, either quietly listening to Beethoven, or else to conversation in which above all an air of sanity prevailed." (Obituary, 1959: 5). Meanwhile, those who worked with in New Zealand would have recalled her "... sound training, unremitting energy, a remarkably co-operative personality, and high intellect ...” (World War II Narrative ..., 1948: 489). Currently, one of Elizabeth Alexander's daughters is preparing a biography of her illustrious mother (Mary Harris, pers. comm., 2002).

\section{INVESTIGATING THE 'NORFOLK ISLAND EFFECT'}

Between 27 March and 1 April 1945, a "very striking” increase in 'radio noise' was noted by the officer in charge of the Royal New Zealand Air Force $200 \mathrm{MHz}$ COL radar unit located on Norfolk Island (see Figure 4 for radar stations mentioned in the text). ${ }^{3}$ This enhancement was shown to originate from outside the radar antenna, turning gear and receiver, and only occurred within half an hour of the rising or setting of the Sun. Furthermore,

The maximum increase of noise was on the bearing of the sun and rotation of the aerial showed noise fluctuations corresponding fairly closely to the radiation diagram of the aerial. At its maximum the noise reached saturation on the azimuth of the sun and peaks of noise were also observed on azimuths corresponding to the first and second pair of side lobes. Switching off the Transmitter had no effect on the noise ... (Alexander, 1945d: 1). 
Elizabeth Alexander was assigned to investigate this phenomenon, which was dubbed the 'Norfolk Island Effect'.

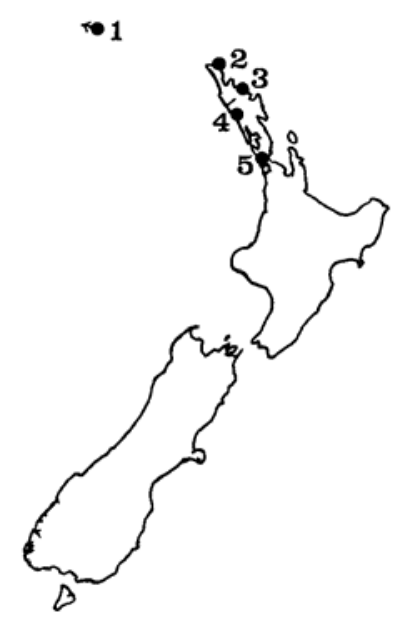

Figure 4. The location of the five RNZAF radar stations involved in solar monitoring in 1945 ( 1 = Norfolk Island; 2 = North Cape; 3 = Whangaroa; 4 = Maunganui Bluff; and 5 = Piha).

Dr Alexander arranged for monitoring of the Sun to take place within an hour of sunrise and sunset at five different RNZAF radar stations: at Norfolk Island, and in the northern sector of the North Island of New Zealand (Figure 4). A contemporary photograph of the Whangaroa radar station is reproduced below in Figure 5. All five stations were instructed “... to record the increase in noise and the azimuth of maximum increase every few minutes and the time observations were taken ... [together with] A general description of the weather at the time of taking the observations ..." (Alexander, 1945d: 1).

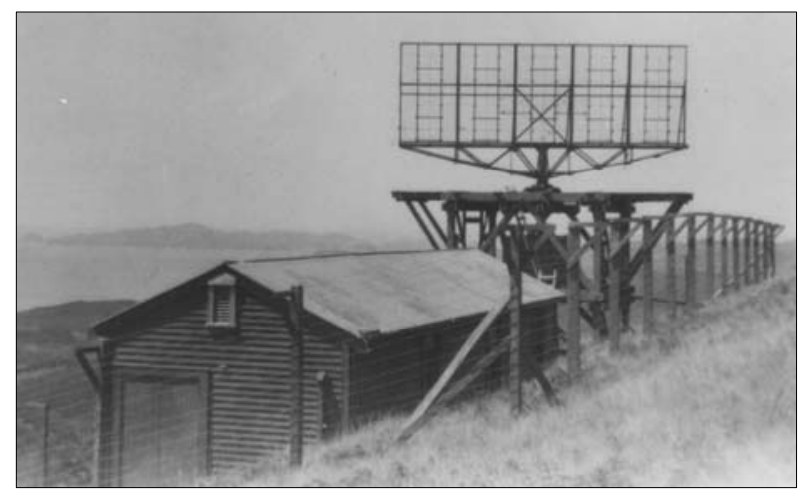

Figure 5. The Whangaroa Radar station, showing the 200 $\mathrm{MHz}$ broad-side array and associated technical building (courtesy: Gordon Burns). 
The monitoring took place between 10 and 23 April, although few stations were able to continue with this project past April 18, and solar detections were recorded at all five stations. But, as Table 1 illustrates, even when all five stations were tracking the Sun, solar radio emission was never detected at more than three of these. It should be noted that the data in Table 1 for Piha are slightly misleading in that on four sunrise observing periods and one sunset observing period the radar antenna had to be used to track aircraft, so solar monitoring was not possible.

Table 1. Days when solar monitoring took place (dashed lines) and when solar radio emission was detected (crosses) at the different RNZAF radar stations

\begin{tabular}{|c|c|c|c|c|c|c|c|c|c|c|c|c|c|c|c|}
\hline \multirow{2}{*}{$\begin{array}{l}\text { Radar } \\
\text { Station }\end{array}$} & \multicolumn{14}{|c|}{ Date 1945 April } & \multirow{2}{*}{$\begin{array}{l}\text { No of } \\
\text { Days }\end{array}$} \\
\hline & 10 & 11 & 12 & 13 & 14 & 15 & 16 & 17 & 18 & 19 & 20 & 21 & 22 & 23 & \\
\hline $\begin{array}{l}\text { Norfolk Island } \\
\text { North Cape } \\
\text { Whangaroa } \\
\text { Maunganui Bluff } \\
\text { Piha }\end{array}$ & - & $\overline{-}$ & $\begin{array}{c}x \\
- \\
-x-\end{array}$ & $\begin{array}{l}- \\
--\end{array}$ & $\begin{array}{l}-x \\
-x\end{array}$ & $\begin{array}{l}x- \\
x-x\end{array}$ & $\begin{array}{l}x \\
-x- \\
--\end{array}$ & $-x-$ & $-x-$ & $-x$ & $-x$ & $-x-$ & & $-x$ & $\begin{array}{l}5 \\
2 \\
5 \\
5\end{array}$ \\
\hline No. of Stations & 0 & 1 & 2 & 2 & 3 & 2 & 2 & 2 & 2 & 1 & 1 & 1 & 0 & 1 & \\
\hline
\end{tabular}

Part of the reason for the inconsistent results indicated in Table 1 lay with the design of the COL radar antennas, which could only rotate in azimuth and detect solar radio emission as the Sun rose or set through the antenna beam. The output, meanwhile, was displayed as 'grass' on a cathode ray tube, and it was a matter of making a subjective assessment as to whether the amplitude of this 'grass' exhibited a meaningful increase. Because the increase was often marginal, this was a problem. In order to increase sensitivity-and provide some means of quantification-the Commanding Officer at the Whangaroa radar station decided to install a microammeter between the receiver output and the diode limiter, and "Immediately a change was apparent and results [were] obtained." (Marsden, 1945: 1). Meter readings of 'normal noise' were taken either side of the Sun and as the radar antenna was slowly swept across the azimuth of the Sun, and up to five sweeps were made when solar noise was detected. Interestingly, "Where more than one complete sweep was taken the azimuth of the noise peaks could be seen to have drifted in the same direction as the changing azimuth of the sun." (Alexander, 1945d: 3). Following this altered modus operandi, solar radio emission was detected at both sunrise and sunset on five successive days (see Table 1 ).

Elizabeth Alexander analysed the April observations made at the five radar stations, and concluded that "... at sunrise and sunset a detectable 
amount of noise over and above normal noise is received from a direction roughly that of the sun." (Alexander, 1945d: 4). She stressed that while the observations were crude "... they do seem to indicate that more energy is sometimes radiated from the sun on $200 \mathrm{Mc} / \mathrm{s}$ than would be expected on black body theory.” (ibid.); in other words, the emission was non-thermal. And while the levels of solar noise seen at the New Zealand radar stations were so small that they might have been missed in the past, she noted that "At Norfolk Island, however, the increase was quite striking." (ibid.).

In a later, much shorter report, Elizabeth Alexander (1945c) noted that on 26 March 1945 'jamming' at the azimuth of the Sun was also detected for 15 to 35 minutes before sunset at two non-New Zealand radar stations. One of these was in the Lingayen Gulf in the Philippines and operated at 106.8 $\mathrm{MHz}$, and the other was an Australian $200 \mathrm{MHz}$ station sited on Montalivet Island in the Darwin area. She concluded that "In both cases the jamming was almost certainly due to Solar Radiation. Probably other stations [in the region] were affected but, as is frequently the case, the phenomenon was not recorded.” (ibid.).

On the basis of the initial New Zealand results, Elizabeth Alexander planned an elaborate solar monitoring program for the second half of 1945, which would involve the original five Air Force radar stations, "... and any Army and Navy stations that can take the observations ..." (Alexander 1945d: 5), and all were to be supplied specially-designed vacuum tube voltmeters (to be inserted immediately after the second detectors in the radar receivers) and calibrated signal generators. The following observing procedure was adopted:

... switch off the transmitter, turn the aerial about $90^{\circ}$ from the sun where the noise is normal, connect the vacuum tube voltmeter and record the meter reading. The signal generator is then connected in and the attenuator adjusted until the vacuum tube voltmeter reading is a little above the normal noise reading. These meter readings and the attenuator reading are recorded. The signal generator is disconnected and the set is ready for noise observations.

When an increase in noise voltage is observed, either of two procedures is adopted. Either the aerial is swept backwards and forwards across the sun's azimuth from normal noise through maximum to normal noise again and meter reading, azimuth and time is recorded every two degrees. Or the aerial is swung just sufficiently to determine the azimuth of maximum noise and meter reading, 
azimuth and time is recorded every one or two minutes. These observations are to be carried out over the sun rise and sunset period daily operational requirements permitting. Weather observations, with particular reference to amount and position of cloud cover, are to be made for each set of measurements. (Alexander, 1945d: 6).

Unfortunately, two factors combined to prevent widespread adoption of this program: (1) an early, successful, outcome of the War was anticipated, so there was on-going reduction of staff at the various radar stations, but despite this (2) there was “... the necessity of keeping up operational watches [which] placed considerable obstacles in the way of a regular observation programme.” (Millar, 1946a: 1). Nonetheless, the five original RNZAF radar stations were able to carry out some solar monitoring. The Norfolk Island station began observations on 24 July, but the other radar units were not in a position to join the program until September, and all continued through into December 1945 (Alexander, 1945c).

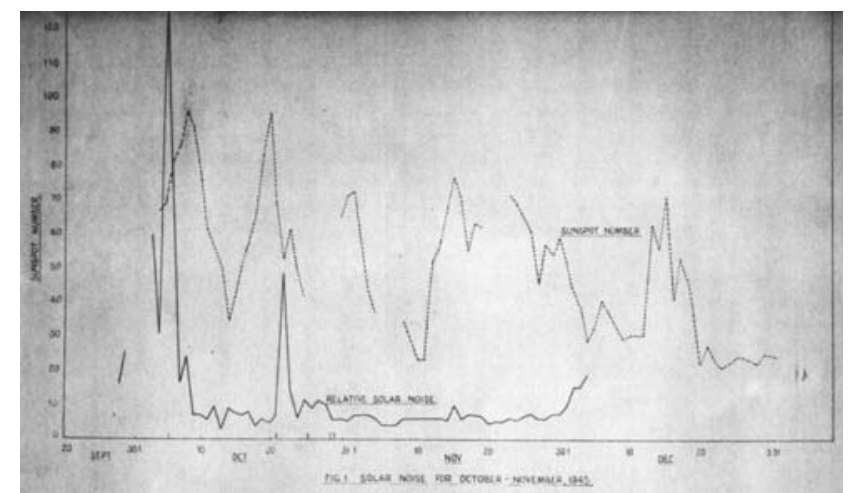

Figure 6. Plot of sunspot numbers, and $200 \mathrm{MHz}$ solar noise recorded at the Norfolk Island and Piha radar stations, September-December 1945 (after Millar, 1946b: 5).

Sadly, this monitoring revealed just the one short-lived period when the Sun was particularly active at $200 \mathrm{MHz}$, centred on October 5 (Millar, 1946a) when " ... violent surges of noise were observed at irregular intervals. These surges were of momentary duration and sent the noise meter needle hard over.” (Alexander, 1945c). When this occurred, the officer in charge of the Piha radar station installed a simple Yagi aerial that could track the Sun, and although the gain was much less than that of the adjacent radar antenna, "... the noise could still be observed, its intensity remaining the same throughout the day whenever the aerial was directed towards the sun ..." (Alexander 1946: 16). Elizabeth Alexander (1945c) also reported that "... The signals fluctuated rapidly but did not completely disappear until sunset.” However, a plot of the solar noise observations made at this time (Figure 6) 
reveals that solar radio emission was also detected on October 21, and that both periods of solar activity correlated with enhancements in sunspot numbers. It is noteworthy that two later periods of higher than average sunspot numbers were not associated with 'solar noise'. Nonetheless, Elizabeth Alexander (ibid.) felt in a position to conclude: "Such evidence as we have so far in New Zealand points to a direct correlation between sunspot number and solar noise ... Though we have no absolute measure of the power received, there is strong evidence that during the periods of intense activity ... Long wave Solar radiation is far removed from black body radiation." The October activity reinforced her view that she was again dealing with non-thermal emission.

At the end of 1945, most of the RNZAF radar stations were closed down, and at the end of January 1946 the Radio Development Laboratory was disbanded and most of the staff returned to their previous positions or to interrupted university studies (Galbreath, 1998; World War II Narrative ..., 1948). But before Elizabeth Alexander and the children sailed for England in July 1946 (Mary Harris, pers. comm., 2002), she had one final radar-related task: to write up an account of her 1945 solar research project. This appeared as a 3-page paper titled "The Sun's radio energy" (Alexander, 1946), and reported the March-April and October activity. The association between sunspots and solar noise-first put forward in her brief December 1945 report-was repeated, and it was noted that both March-April and October 1945 were periods of notable sunspot activity. She also mentioned the non-thermal nature of the $200 \mathrm{MHz}$ emission, but was premature in stating that "To deduce solar temperatures of millions of degrees from this radiation, as has been suggested in some press reports, is absurd." (Alexander, 1946: 20). Later that same year, Martyn (1946) and Pawsey (1946) published papers in Nature in which evidence of a coronal temperature of 1 million degrees was presented. In her paper, Elizabeth Alexander (1946) also discussed wartime observations of solar radio emission made by other researchers, in England, Australia and the USA; some of these projects were only undertaken after receipt of her reports on the "Norfolk Island Effect".

Elizabeth Alexander ends her 1946 paper by pointing to the need for further research, and suggesting a role for amateur astronomers and radio enthusiasts:

What is required at the moment is more experimental evidence on the following aspects:- 
1. The way the received power varies with wavelength, over the whole band of the shortest microwaves up to the largest wavelengths (15-metres) which will penetrate the ionosphere (it almost looks at present as if the power might be greater at longer wavelengths).

2. The variation, at all wavelengths, with angle of elevation of the sun. This will permit evaluation of atmospheric absorption.

3. Exact times of onset, cessation, or change in character. This will permit correlation either with visible changes in the sun, or with other associated phenomena, magnetic storms, etc., and might lead to methods of predicting radio fadeouts.

4. Seasonal fluctuations, and variation with geographical position, particularly latitude.

In observations of this type, amateurs can play an important part. Anyone who cares to build an ultra-shortwave receiver can be fairly sure of collecting useful information. The time is appropriate, since the sun is just entering a new phase of activity, and sunspots may be expected with increasing frequency over the next few years. (Alexander, 1946: 20).

The tragedy is that Elizabeth Alexander's interesting little paper appeared in the inaugural issue of a New Zealand-based journal titled Radio \& Electronics, which at the time had virtually no international visibility, and certain never came to the attention of radio astronomers-or indeed those researching the history of radio astronomy-until very recently. Nor did Elizabeth send out reprints (if indeed any were issued), or maintain a correspondence with colleagues she had met who were involved in the formative days of British and Australian radio astronomy. So her pioneering research was soon be forgotten, only to be rescued from obscurity when Woody Sullivan (1988) came upon archival reference to the 'Norfolk Island Effect' in the course of his research on the world-wide development of radio astronomy.

\section{DISCUSSION}

\subsection{The Radiophysics Solar Program}

On 1 August 1945, Elizabeth Alexander penned a letter to J.L. Pawsey at the Radiophysics Laboratory in Sydney, and included as an attachment a copy of her R.D. 1/518 report on the 'Norfolk Island Effect', which “... describes our present and proposed investigations ...” (Alexander, 1945a). 
Pawsey passed the letter and report on to the Chief of the Division, Dr Briton, and they were also seen and initialed by Deputy-Chief, Taffy Bowen, Frank Kerr, Lindsay McCready and Ruby Payne-Scott. The contents of Alexander's letter and report created considerable interest in Sydney, and were partly responsible for the launch of the Division's solar radio astronomy research program. After perusing this material, Taffy Bowen (as Acting Chief of the Division of Radiophysics) wrote to Dr Ernest Marsden in New Zealand: "We were very interested to hear about the radar observations ... and will attempt to repeat them here in Sydney." However, this was not the only intelligence on solar radio emission to arrive at this time, for Ruby Payne-Scott (1945) reveals

... the almost instantaneous arrival of three reports in the [Radiophysics] laboratory, one recording severe noise interference in the direction of the sun on G.L. stations (55 - $85 \mathrm{Mc} / \mathrm{s}$.) on 27th and 28th February 1942, coinciding with the passage of a large sunspot, another reporting ... [the] Norfolk Island [Effect] ... and a recent report by Reber in which he mentioned that, using his equipment for plotting "cosmic static" on $160 \mathrm{Mc} / \mathrm{s}$., he obtained considerable radiation when the aerial was pointed at the sun.

Payne-Scott's report (ibid.) also indicates that it was these three reports that collectively inspired her and two colleagues to conduct the first Australian search for solar radio emission.

These observations were made from 3 to 23 October 1945 using the 200 $\mathrm{MHz}$ COL radar antenna at the Royal Australian Air Force's radar station at Collaroy, a northern Sydney beachside suburb, and revealed the presence of solar radio emission. Moreover, variations in mean intensity were found to correlate with changes in the total area of visible sunspots. When they came to write up these observations for Nature, Pawsey, Payne-Scott and McCready (1946) specifically mentioned Elizabeth Alexander's work, and one of the four references listed at the end of the paper was her 1945 report.

The paper was completed on 23 October 1945 and immediately submitted to Nature, but by the time it appeared in the 9 February 1946 issue it had been foreshadowed by two other contributions. The first of these was penned by Sir Edward Appleton, dated 24 September 1945, and was published on 3 November. It discussed the evidence for non-thermal radio emission from the Sun (Appleton, 1945). The other paper, dating from 17 October 1945, was by H.S. Hey, and it appeared in the 12 January 1946 issue of Nature (Hey, 1946). This important contribution reported on 1942 
detection of solar radio emission at radar stations in England, publication of which was only possible once that the war was over and the research no longer carried a classified 'tag'.

When quizzed by the Australians about the publication order of the three papers, and the lengthy delay in appearance of the Sydney paper, Appleton replied:

I am sure your people were only anxious to acknowledge prior work ... I have been much concerned with this solar noise myself and so know the history of it fully. Fortunately for us, my letter and Hey's letter to Nature preceded the Australian one, so no harm was done, as it turned out, so far as we are concerned; though I feel rather sorry about the New Zealand people who were the next to conclude that it was really radio noise in their Norfolk Island experiments. (Appleton, 1946; his underlining; my italics).

Despite these protestations of concern, it is telling that Appleton neglected to mention Elizabeth Alexander's research in his paper, even though he was fully aware of the New Zealand work and the non-thermal nature of the emission by mid-1945. More than this, at some time prior to 1 August 1945 Appleton claims to have even gone to the trouble of replicating the New Zealand observations (see Alexander, 1945a), yet he also fails to mention this additional evidence for non-thermal emission in his Nature paper. By this stage, Sir Edward was already beginning to gain a reputation for claiming credit for other people's work, and helping delay the publication of papers submitted to Nature by those he viewed as 'competitors' (e.g. see Bowen, 1985; Kerr, 1987), and at the time Taffy Bowen (1946) wrote Dr Frederick White at CSIRO Head Office: "I am sorry that Appleton is making a song and dance about our letter to "Nature", but I suppose he is just expressing his well-known "ownership" of all radio and ionospheric work." (Bowen, 1946).

After their initial observations at Collaroy, Pawsey and his Radiophysics colleagues decided to mount an even more ambitious solar monitoring program, extending from October 1945 through to March 1946. At first this involved the $200 \mathrm{MHz}$ radar units at Collaroy and Dover Heights, but the limitations of sea interferometers soon prompted them to install $200 \mathrm{MHz}$ steerable Yagi arrays at Collaroy, Dover Heights, the North Head radar station, and at Mount Stromlo Observatory. A few observations were also made at 75 and $3000 \mathrm{MHz}$. The results of this major investigation were published in the prestigious Proceedings of the Royal Society (McCready, 
Pawsey and Payne-Scott, 1947)—again after inordinate and inexplicable delays - and Elizabeth Alexander's work was once more referred to and referenced: the authors specifically state that "Observations on 200 Mcyc./sec. similar to those of the New Zealand stations were begun by us towards the end of 1945 ..." (McCready et al., 1947: 358, my italics). McCready et al. were not only able to confirm the New Zealand findings, but to make important new contributions to solar radio astronomy, thus placing Australia's foray into this emerging discipline on a firm observational and theoretical footing (for further details, see Orchiston, Slee and Burman, 2005).

\subsection{The New Zealand Sequel}

One of Elizabeth Alexander's principal preoccupations in 1944-1945 was radio-meteorology, which led to the 'Canterbury Project'. This joint British-New Zealand research project was approved in 1945, but the end of the War delayed its launch as funding had to be re-negotiated under civilian peace-time conditions (see Alexander, 1945b). Given Elizabeth Alexander's relocation to England, the Canterbury Project came under the direction of one of her associates, Dr Bob Unwin, and in early 1947 an ex-WWII radar antenna and field trucks were set up at Wakanui Beach on the Canterbury coast, 85-km southwest of Christchurch (Figure 7). In October 1947 the field station was transferred to Ashburton Airport (Unwin, 1947). Although this equipment was intended for the study of radio propagation across the Canterbury Plains under varying meteorological conditions, Dr Unwin arranged for his staff to observe the Sun at $97.5 \mathrm{MHz}$ for an hour and a half after sunrise and before sunset from March to December 1947, and “... a large number of solar bursts of short duration were detected. On many occasions these occurred when sunspots and other visual signs of solar activity were in evidence.” (Orchiston, 1994: 68). The observations were forwarded to Ivan Thomsen at the Carter Observatory in Wellington, and it is to be regretted that he never published the results of this interesting study.

On 23 November 1945 Elizabeth Alexander (1945b) warned Joe Pawsey that New Zealand's solar radio astronomical future looked bleak after the close-down on the COL radar stations at the end of the year: "I doubt that New Zealand will be able to put sufficient effort into building aerials adequate to investigate the phenomenon. It is a large scale job, if it is to be done properly, and the Canterbury Project is taking all available men and cash." This forecast proved remarkably accurate, and the part-time excursion into solar radio astronomy during the Canterbury Project was all 
that staff from the DSIR were able to attempt. Unlike in Australia, where many of the staff at the Radiophysics Laboratory were retained after the war (and became the nucleus of the Sydney radio astronomy group), most of those in New Zealand's Radio Development Laboratory left the DSIR; and although Marsden succeeded in forming a Radar Section within the Dominion Physical Laboratory on 21 February 1946 (World War II Narrative ..., 1948), this began with a staff of just 13 (Atkinson, 1976: 66) and would always be a small-scale operation with limited funding and research capability. Within post-War Government-funded science, there simply was no place for radio astronomy in New Zealand, and it was left to other institutions and individuals to progress this discipline. Those that were involved in solar radio astronomy prior to 1950 are discussed below.

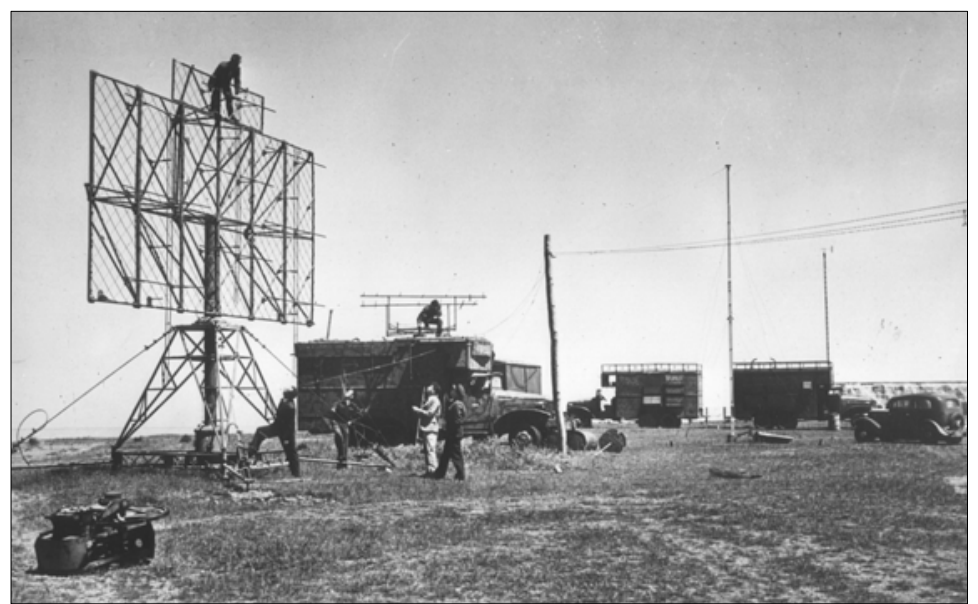

Figure 7. Installation of the 'Canterbury Project' $97.5 \mathrm{MHz}$ radar antenna at Wakanui Beach near Ashburton. In the background are associated equipment trucks (courtesy: Bon Unwin).

While the Canterbury Project was in progress, a student named Alan Maxwell was engaged in a solar radio astronomy project for his M.Sc. degree at what is now the University of Auckland (see Maxwell, 1948). His supervisor was Dr K.S. Kreielsheimer, and he also found ready support from Professor P.W. Burbidge, both of whom were interested in astronomy, radiophysics and upper atmospheric physics. In mid-1947 Maxwell erected twin Yagis on the roof of the Biology Department (Figure 8), and tracked the Sun at $100 \mathrm{MHz}$ for the remainder of the year and into the second half of 1948. Maxwell (1948: 82) found that "In general, when solar noise was received there were sunspots on or near the sun's meridian.” Of special interest was "... a period of solar activity between 1948 August 5-9, when there were numerous small-scale bursts of radio noise." (Orchiston, 1994: 69), and "On at least two days an indication of a general solar noise 
background was noticed by pointing the array into and away from the sun ... [Furthermore] A rough correlation of bursts with those observed in Canterbury [at Ashburton] has been established on several occasions.” (Burbidge and Kreielsheimer, 1947). Despite this being one of the first postgraduate theses on solar radio astronomy ever written anywhere in the world, Maxwell also failed to publish his work-it simply was not the custom at this time-and soon after completing his studies he moved to the dynamic astronomical environment of Jodrell Bank (at the University of Manchester) where he was quickly immersed in new research for a Ph.D. (Alan Maxwell, pers. comm., 1993). Later he would go on to build an international reputation in solar radio astronomy while at Harvard College Observatory and the Radio Astronomy Station at Fort Davis, Texas.

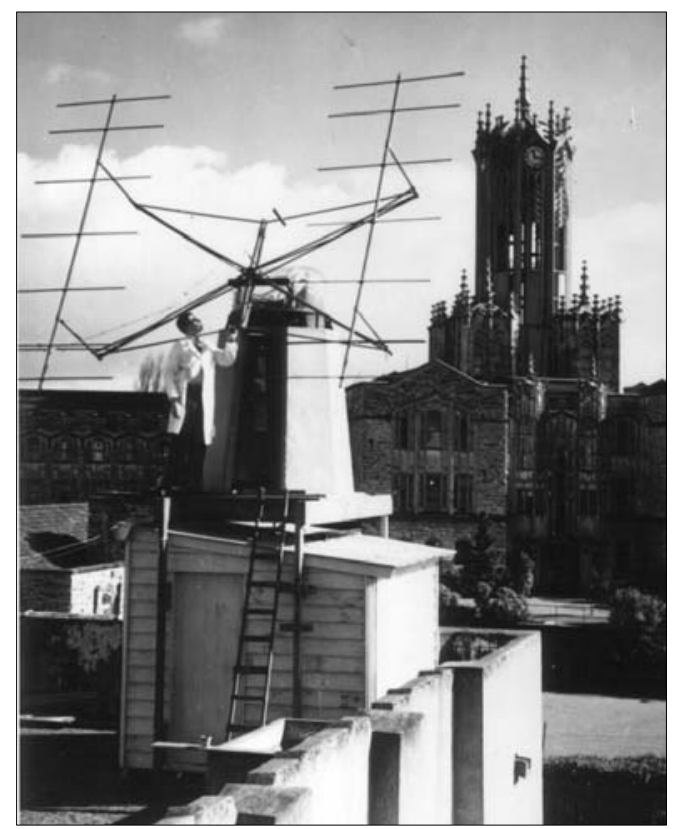

Figure 8. Alan Maxwell adjusting the $100 \mathrm{MHz}$ twin Yagi antenna set up on the roof of the Biology Building at Auckland University College in 1947. The small hut below that antenna and mounting housed the receiver (courtesy: Alan Maxwell).

Carter Observatory in Wellington specialized in optical solar monitoring, and from the start its Director, Ivan Thomsen, was vitally interested in the projects carried out by Elizabeth Alexander and Alan Maxwell and supplied both with relevant optical data. While his involvement in the solar radio monitoring associated with the Canterbury Project was disappointing (in that no results were published), he did in fact publish one paper pertaining to solar radio astronomy. Thomsen (Co-ordination ..., 1947) was particularly 
interested in the relationship between solar emission, sunspots and solarterrestrial effects — such a short-wave radio fadeouts—and the 24 January 1948 issue of Nature features a paper where he compares Ryle and Vonberg's (1947) radio data for December 1946-April 1947 with sunspot records and finds “... a surprisingly general agreement.” (Thomsen, 1948: 134). Looking more closely, when the general level of radio emission for February-March 1947 was plotted against the position of photospheric features recorded at the Carter Observatory (Figure 9), “... it was nearly always possible to ascribe some significant sunspot group to each of the maxima of the [radio] curve ..." (Thomsen, 1948: 134-135). Furthermore, the radio emission tended to coincide with the central meridian passage of the associated spot group, and “... in general, groups in the early stages of vigorous development, or showing activity by large umbral movements and changes and accompanied by flares, give the greatest emission." (Thomsen, 1948: 135).

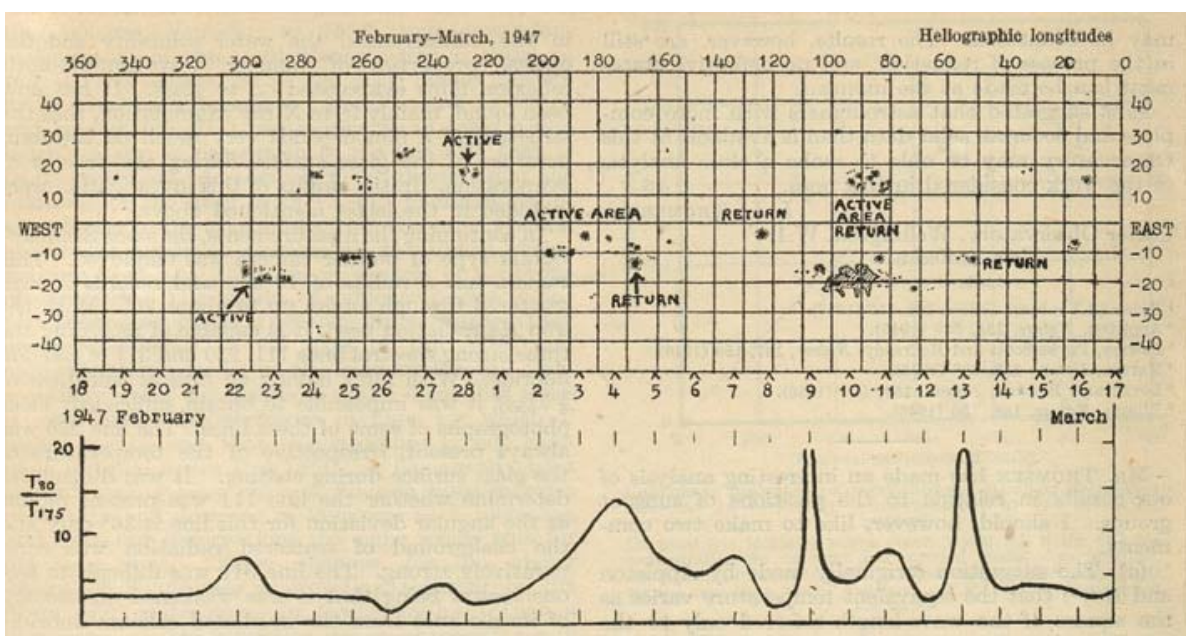

Figure 9. Plot of solar radio emission in February-March 1947 and associated photospheric features (after Thomsen, 1948: 135).

Surprisingly, New Zealand can boast a fourth solar radio astronomy project dating to the immediate post-War years. Perhaps inspired by Elizabeth Alexander's 1946 'call to arms', Kaiapoi's Robert Francis Joyce constructed a corner reflector that could track the Sun, obtained an ex-WWII radar receiver, and from mid-1949 carried out solar monitoring at $515 \mathrm{MHz}$, sending his records to Ivan Thomsen at the Carter Observatory. By avocation, Joyce was a well-known amateur astronomer, whose Neptune Observatory boasted a much-used 11.4-cm (4.5-in) Wray refractor, and he was an ardent astronomical photographer (see Howell, 1967; Murray Geddes ..., 1956). By vocation he ran a radio manufacturing and repair business, so 
he was in an ideal position to tap into the newly-emerging field of solar radio astronomy.

\section{CONCLUDING REMARKS}

New Zealand was merely one of several countries involved in the secret investigation of solar radio emission during WWII, and the person responsible for this Antipodean research was a British-born scientist, Dr Elizabeth Alexander. Rare amongst New Zealand-based scientists at the time, she was a woman, was married with a young family, held a senior post in the Department of Scientific and Industrial Research, and therefore moved in the upper echelons of New Zealand science (see Figure 10). Being somewhat older than most of her colleagues, she had a wealth of research experience to fall back upon when investigating the 'Norfolk Island Effect', and it is fortunate that her academic training as a geologist at Cambridge included units in physics and mathematics.

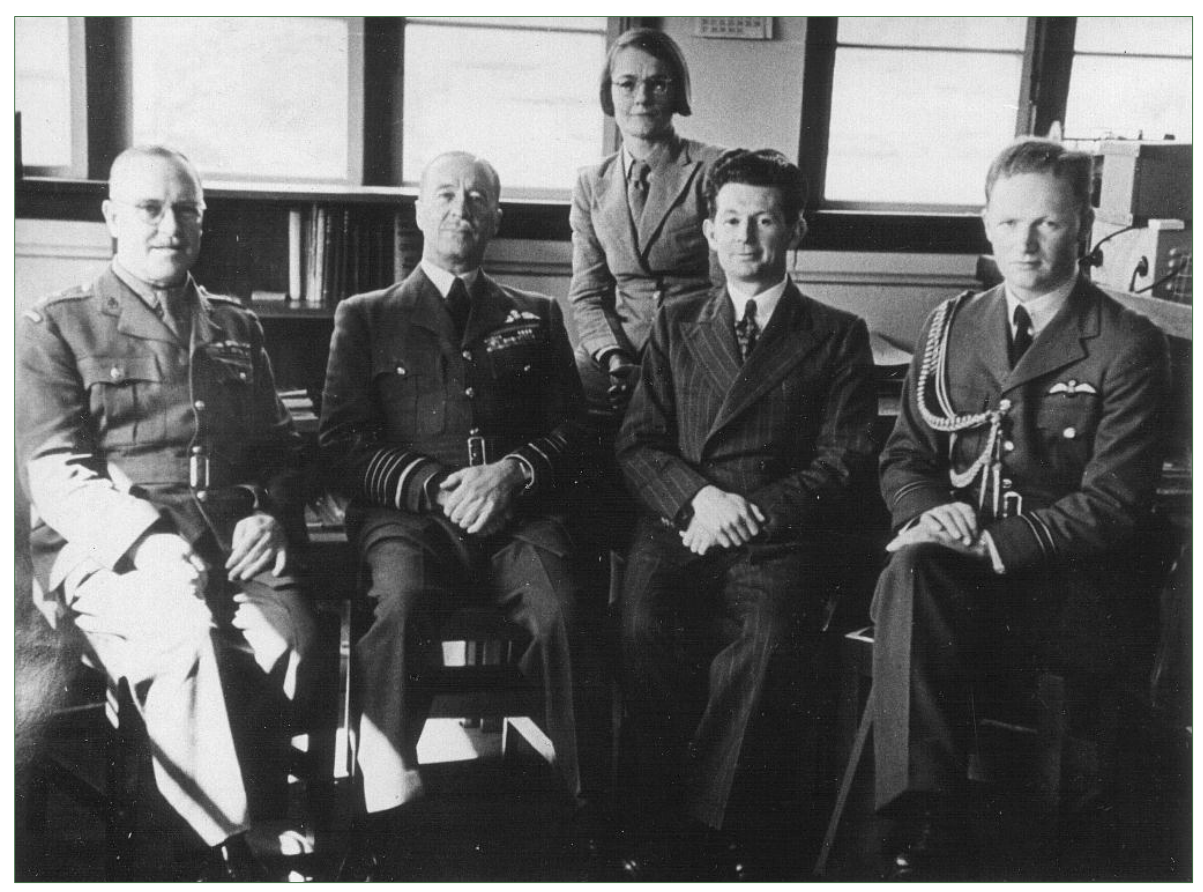

Figure 10. In September 1944 Dr Elizabeth Alexander poses with (left to right) Dr Ernest Marsden (Director of Scientific Developments, DSIR), Sir Cyril Newall (the Governor General of New Zealand), Dr Ian Stevenson (Director of the Radio Development Laboratory) and the Governor General’s Aide de Camp (courtesy: Professor E.R. Collins). 
As it turned out, the 'Norfolk Island' project was but a momentary diversion in a long and eventful career dominated by geology and academia, but it was a significant diversion nonetheless, for by being in the right place at the right time she ended up being the first women to conduct research in the fledging new discipline of 'radio astronomy' (although it would take another five years of intensive research-mainly in England and Australiabefore this term would begin to find common usage).

Her solar work in 1945 was the catalyst that led to several other New Zealand research projects in solar radio astronomy in the immediate postWar years, yet unlike in neighbouring Australia, this discipline did not succeed in gaining a sustained foothold in New Zealand at this time. Had Elizabeth Alexander remained in New Zealand after the war and been able to pursue her interests in radio astronomy and radio-meteorology-instead of returning to geology and academia in Singapore-then the situation may very well have been quite different.

Nonetheless, Elizabeth Alexander was a remarkable woman, and her place in the annals of radio astronomy deserves to be fully recognized and applauded.

\section{ACKNOWLEDGEMENTS}

I am grateful to Jean Archibald (Edinburgh University Library), Gordon Burns (Wanganui, NZ), Professor E.R. Collins (Mahurangi East, NZ), Ross Galbreath (Tuakau, NZ), Phyllis Hetzel (Newnham College, Cambridge), Ms Kan Sok Cheng (National University of Singapore Library), Dr Alan Maxwell (Harvard-Smithsonian Center for Astrophysics), Dr Mark Nicholls (Cambridge University Library), Dr Bruce Slee (Australia Telescope National Facility), Professor Woody Sullivan (University of Washington), the late Dr Rob Unwin (Wanaka, NZ), Dr Richard Wielebinski (MPIfR, Bonn), Dr R.M. Williams (Wellington, NZ), staff at the National Archives of New Zealand (Wellington), and especially Elizabeth Alexander's three children, Mary Harris (London), Bernice Jones (Edinburgh) and Bill Alexander (Leamington Spa), for providing information relating to this project. I am also grateful for a grant from the Kammeyer Fund, which made it possible for me to attend the Woodfest Conference where an earlier version of this paper was presented. Finally, I should like to thank Mary Harris, Gordon Burns, Alan Maxwell and Professor Collins for permission to publish Figures 1, 2, 3, 5, 8 and 10. 


\section{NOTES}

1. Short, semi-popular accounts of the Elizabeth Alexander's research are presented in Orchiston, 1994; Orchiston and Slee, 2002: 25-26; and Sullivan 1988: 316.

2. The Radio Development Laboratory was a Division of the Government's Department of Scientific and Industrial Research, and was set up in 1941 under Dr Owen Pulley with an initial staff of $\sim 100$. Based in Wellington (see Figure 2), it had branches in Auckland and Christchurch. When Pulley returned to Australia in 1942, C.N.M. Watson-Munro became Director of the Laboratory (for details, see Galbreath, 1998). According to Elizabeth Alexander's husband, Norman (later Sir Norman), her appointment was partly facilitated through 'the old-boy network', as they both knew Pulley, and people like Taffy Bowen, Joe Pawsey and Fred White who played key roles in the development of radar in Australia (Alexander, early 1990s).

3. At an approximate longitude of $168^{\circ} \mathrm{E}$ and latitude of $29^{\circ} \mathrm{S}$, Norfolk Island is located about $1,400 \mathrm{~km}$ east of Brisbane and $750 \mathrm{~km}$ northwest of the northern-most tip of New Zealand's North Island. Although considerably closer to New Zealand, it is Australian territory. When the USA set up separate command areas in the Pacific in 1941 Norfolk Island fell within the New Zealand (South Pacific) command rather than the Australian (Southwest Pacific) command, and this explains why a Royal New Zealand Air Force radar station was established there. The radar station was located ".. at a height of 1,000 feet near the north western corner of Norfolk Island ... [with] an unobstructed view all round ...” Alexander (1945d: 2).

\section{REFERENCES}

A.J.B., 1959. Frances Elizabeth Somerville Alexander (née Caldwell). Proceedings of the Geological Society of London, 1572, 140-141.

Alexander, F.E.S., 1945a. Letter to J.L. Pawsey, dated 1 August. Copy in Sullivan Collection.

Alexander, F.E.S., 1945b. Letter to J.L. Pawsey, dated 23 November. Copy in Sullivan Collection.

Alexander, F.E.S., 1945c. Long wave solar radiation. DSIR, Radio Development Laboratory (Report).

Alexander, F.E.S., 1945d. Report on the investigation of the "Norfolk Island Effect". DSIR, Radio Development Laboratory Report dated 1 August (R.D. 1/518).

Alexander, F.E.S., 1946. The Sun's radio energy. Radio \& Electronics, 1(1), 16-17, 20.

Alexander, Sir Norman, early 1990s, with a Footnote by Mary Harris dated 2002. Elizabeth's war work. Manuscript.

Appleton, E.V., 1945. Departure of long-wave solar radiation from black-body intensity. Nature, 156, 534-535. 
Appleton, E.V., 1946. Letter to Dr F.W.G. White, dated 4 March. Copy in Sullivan Collection.

Atkinson, J.D., 1976. DSIR's First Fifty Years. Wellington, Department of Scieitifc and Industrial Research.

Bowen, E.G., 1945. Letter to Dr Ernest Marsden, dated 27 July. Copy in Sullivan Collection. Bowen, E.G., 1946. Letter to Dr. F.W.G. White, dated 26 April. Copy in Sullivan Collection. Bowen, E.G., 1985. Letter to Woody Sullivan dated 7 August. In Sullivan Collection.

Burbidge, P.W., and Kreielsheimer, K.S., 1947. Report on solar noise measurements carried out at the Physics Department, Auckland University College. Unpublished report prepared for a DSIR meeting on 6 November 1947. Copy in National Archives, Wellington.

Co-ordination of research on auroral, solar, ionospheric, geophysical and radio phenomena. Memorandum to interested parties (1947). Report prepared for a DSIR meeting on 6 November 1947. Copy in National Archives, Wellington.

Galbreath, R., 1998. DSIR. Making Science Work for New Zealand. Themes From the History of the Department of Scientific and Industrial Research. Wellington, Victoria University of Wellington Press, in association with the Historical Branch, Department of Internal Affairs.

Hey, J.S., 1946. Solar radiations in the 4-6 metre radio wave-length band. Nature, 157, 47-48.

Howell, P., 1967. Robert Francis Joyce. An appreciation. Southern Stars, 22, 51-53.

In memoriam. Frances Elizabeth Somerville Alexander (née Caldwell), 1908-58. Newnham College Roll Letter, January, 36-37 (1959).

Kellermann, K., and Sheets, B. (eds.), 1983. Serendipitous Discoveries in Radio Astronomy. Green Bank, National Radio Astronomy Observatory.

Kerr, F., 1987. Letter to Woody Sullivan, dated 6 April. In Sullivan Collection.

Lovell, B., 1977. The effects of defence science on the advance of astronomy. Journal for the History of Astronomy, 8, 151-173.

McCready, L.L., Pawsey, J.L., and Payne-Scott, R., 1947. Solar radiation at radio frequencies and its relation to sunspots. Proceedings of the Royal Society, A, 190, 357-375.

Marsden, E.D.L., 1945. Report on radio sunset-sunrise observations taken at No. 7 radar unit for the period 14th until 18th April, 1945. DSIR (Report).

Martyn, D.F., 1946. Temperature radiation from the quiet Sun in the radio spectrum. Nature, 158, 632-633.

Maxwell, A., 1948. Enhanced Solar Radiation at 3 Metre Wavelengths. M.Sc. Thesis, Physics Department, Auckland University College.

Millar, J.G., 1946a. Long wave solar research. DSIR Report dated 15 January.

Millar, J.G., 1946b. Observations of noise from the Sun at metre wavelengths on Norfolk Island and in New Zealand. DSIR, Radar Section, Dominion Physical Laboratory (Report 1/536).

Murray Geddes Prize Award-1955. Mr. R. Francis Joyce. Southern Stars, 17, 6 (1956).

Obituary. Elizabeth Alexander. Ibadan, 5, 4-5 (1959).

Orchiston, W., 1994. Radio waves from the Sun: the New Zealand connection. In Orchiston, W., Dodd, R., and Hall, R. (eds.). Astronomical Handbook for 1995. Wellington, Carter Observatory. Pp. 65-69.

Orchiston, W., and Slee, B., 2002. The Australasian discovery of solar radio emission. AngloAustralian Observatory Newsletter, November, 25-27.

Orchiston, W., Slee, B., and Burman, R., 2005. The genesis of solar radio astronomy in Australia. Journal of Astronomical History and Heritage, 8, in press.

Pawsey, J.L., 1946. Observation of million degree thermal radiation from the Sun at a wavelength of 1.5 metres. Nature, 158, 633-634.

Pawsey, J.L., Payne-Scott, R., and McCready, L.L., 1946. Radio-frequency energy from the Sun. Nature, 157, 158-159.

Payne-Scott, R., 1945. Solar and cosmic radio frequency radiation. Survey of knowledge available and measurements taken at Radiophysics Lab. to Dec. 1st 1945. Sydney, CSIR, Radiophysics Division (Report SRP 501/27).

Reber, G., 1944. Cosmic static. Astrophysical Journal, 100, 279-287. 
Ryle, M., and Vonberg, D.D., 1947. Relation between the intensity of solar radiation on 175 Mc./s. and 80 Mc./s. Nature, 160, 157-159.

Schott, E., 1947. 175 MHz emission of the Sun. Physikalische Blätter, 3, 159-160.

Southworth, G.C., 1945. Microwave radiation from the Sun. Journal of the Franklin Institute, 239, 285-297.

Sullivan, W., 1988. Early days of Australian radio astronomy. In Home, R. (ed.). Australian Science in the Making. Cambridge, Cambridge University Press. Pp. 308-344.

Thomsen, I.L., 1948. Solar radio emissions and sunspots. Nature, 161, 134-136.

Unwin, R.S., 1947. Notes on observations of solar noise at 3 metres wavelength made at Canterbury Project, Ashburton. DSIR Report dated 29 October (original in National Archives, Wellington).

Unwin, R.S., 1992. The development of radar in New Zealand in World War II. The Radioscientist, 3(1), 8-18.

World War II Narrative No. 3. Radar. Wellington, DSIR (1948). Original Manuscript in National Archives, Wellington (W3424, Box 16). 